\title{
The Impact of Economic Growth on Pollution in Developed European Countries
}

\author{
Lamia Jamel $^{1} \&$ Samir Maktouf ${ }^{2}$ \\ ${ }^{1}$ Department of Economics, Faculty of Economic Sciences and Management of Sousse, Sousse University, \\ Tunisia \\ ${ }^{2}$ Department of Economics, Faculty of Economic Sciences and Management of Tunis, Tunis University, Tunisia \\ Correspondence: Lamia Jamel, Department of Economics, Faculty of Economic Sciences and Management of \\ Sousse, Sousse University, Tunisia, 184 Street Ahmed Hamza, Sahloul 1 Sousse, Tunisia. Tel: 21-692-104-779. \\ E-mail: lajamel@yahoo.fr
}

Received: February 9, 2018; Accepted: March 17, 2018; Published: April 22, 2018

\begin{abstract}
In our study, we empirically examine the influence of economic growth on environmental degradation in the developed European economies through the period of study beginning in 1985 to 2015. For the econometric methodology, we employ the Cobb-Douglas production function. From the tests of cointegration (Kao and Fisher tests), we corroborate the existence of a cointegration nexus among the economic growth and pollution. Also, we confirm the hypothesis of basic EKC which assumes the existence of a bidirectional relationship between economic growth and emissions of CO2 in developed European countries during the period of study (1985-2015). In addition, we conclude that there is a two-way causal nexus among energy consumption and pollution in developed European countries.
\end{abstract}

Keywords: Economic growth, pollution, developed European countries, financial development

\section{Introduction}

Different countries have withstood the exclusive achieving economic growth while observing an increase in carbon dioxide (CO2). Then there was a growing apprehension about the technique of "low $\mathrm{CO} 2$ emissions and green growth." Especially considering whether it is really possible to achieve steady economic growth not including the increase in energy consumption of gas.

The developed and developing countries disagree that some $\mathrm{CO} 2$ Energy constraints would slow economic growth and suggested that industrialized countries should augment funding to reduce total warming, which is widely marked because of strong gas emissions from industrial economies. This question is reasonably related to post-Kyoto negotiations on climate vary, and therefore, it is essential to look at the connection between environmental degradation and economic growth with several empirical examination tools.

In this alignment, the causal link among economic growth and energy consumption was considered by many significant academic researchers in recent decades. Several works have focused on different economies, different time, a variety of modeling methodologies and diverse substitution variables that were employed for the link among CO2 emissions, energy utilization and economic development (Baranzini et al, 2013; Ghosh, 2010; Stern, 1993; Wolde-Rufael, 2005; Yuan et al., 2007). However, their results are mixed and failed to unique findings (Chen et al., 2007).

Several investigations have studied the causal relationship between energy consumption, $\mathrm{CO} 2$ emissions and economic development. However, these results have find mixed results, calling for further study to explain this link. Several studies have investigated the link among economic development, energy utilization, financial development, openness trade and $\mathrm{CO} 2$ emissions by utilizations diverse econometric methodologies.

In this paper, we will empirically study the impact of economic growth on pollution for all developed European economies through the period from 1985 to 2015. We will use the tests of the unit root tests cointegration, estimation by FMOLS and DOLS method and causality test Granger. We conclude the existence of a cointegration nexus among the economic development and pollution. Also, we confirm the hypothesis of basic EKC which assumes the subsistence of a bidirectional link among economic development and emissions of $\mathrm{CO} 2$ in developed 
European countries through the period of study (1985-2015). In addition, we show the existence of a two-way causal nexus among energy utilization and pollution in developed European countries.

The rest of this paper is planned as follow: in Section 2, we present a review of literature on the link among GDP and pollution. In Section 3, we present the econometric method employed in this study. In section 4, we present the dataset utilized for the empirical validation. Section 5 finds the empirical results. Section 6 concludes.

\section{Literature Review}

To examine the impact of economic activity indicators of environmental degradation, Omri (2013) use the method of generalized least squares throughout the period 1990-2011 for countries in the MENA region. It uses CO2 as an indicator of pollution and labor, capital, population, financial development, and GDP as an indicator of economic activity. Their results show the presence of a significant positive impact in GDP and the negative impact of financial development and capital on $\mathrm{CO} 2$ emissions.

Shahbaz et al. (2013) use the error correction vector model and the GC to study the impact of GDP, energy consumption, foreign direct investment, financial development, and trade openness on pollution environment during the period from 1971 to 2011 in the case of Malaysia. They show that the GDP consumption, energy, foreign direct investment, financial development, and trade openness have a positive effect on $\mathrm{CO} 2$ emissions.

Baek and Pride (2014) develop a survey to a sample of countries in the largest nuclear production during the period 1990-2011. Econometrically, these authors use the vector autoregressive model and Johnsen cointegration. They employ $\mathrm{CO} 2$ as an indicator of pollution. For economic indicators, they use the GDP and the production of nuclear electricity. Their results showed that economic indicators have a positive impact on the pollution of these countries.

Farhani et al. (2014) exploit by GC errors vectors correction model for the case of Tunisia (1971-2008). They utilize $\mathrm{CO} 2$ emissions, GDP, energy use, and trade openness to investigate the indicators of economic activity of the effect on pollution. Their empirical results prove the presence of a positive causality between $\mathrm{CO} 2$ emissions and economic indicators.

Charfeddine and Ben Khediri (2016) utilize unit root tests with multiple structural breaks and cointegration techniques switching scheme considering for one and two unknown regime moves to examine the relationship between $\mathrm{CO} 2$ emissions, electricity use, economic development, financial development, trade liberalization, and urbanization in the UAE during the period 1975-2011. The empirical results of their study show the existence of Environmental Kuznets Curve (EKC). In addition, Charfeddine and Ben Khediri (2016) explain an inverted U relationship amid financial development and emissions of carbon dioxide. In addition, they find that electricity utilization, urbanization, and openness trade help to improve environmental quality.

The primary goal of any economy is to make the most of economic development to achieve its place in the developed economies of the world, which makes the reply of the environment to the very precise and crucial economic development because economic growth influences 'natural environment. It is known that economic growth at the expenditure of the quality of the environment; but, it is also highlighted that developed economies may introduce environmentally friendly technology, which in turn will make the most excellent environment to live.

After the prediction (Kuznets, 1955) that the changing relationship amid environmental quality and income per capita and income inequality takes the form of an inverted $U$ on the assumption of the EKC. Thus, the quality of the environment is first compounded by the country's economic expansion, but after winning enough growth to a threshold level of economic growth can improve the quality of the environment and is a U-shaped curve reversed between them.

Jamel and Derbali (2016) investigate empirically the effect of energy utilization and economic development on the environmental degradation as measured by $\mathrm{CO} 2$ emissions. They employ the cointegration test, the fully modified OLS, and the panel causality to study the causality amid environmental pollution and economic aggregates from a panel data of eight Asian economies through the period 1991-2013. They find that the cointegration tests confirm long run relationship among environmental degradation and energy consumption and economic growth along with financial development, trade openness, capital stocks, and urbanization as control variables. In addition, FMOLS estimation results confirm that economic development and energy utilization have a positive and significant effect on environmental degradation. Besides, panel causality through VECM verifies that bidirectional causal connection is found amid energy utilization and economic development and environmental degradation.

Jamel and Maktouf (2017) explore empirically the causal link amid economic growth (GDP), CO2 emissions (environmental degradation), financial development, and openness trade with the ordinary least squares technique 
for a yearly panel data of 40 European economies, through the period of study beginning on 1985 to 2014 . To examine this fundamental link, they exploit the Cobb-Douglas production function. Their empirical conclusions point to a bidirectional Granger causal linkage amid GDP and pollution, GDP and financial sector development, GDP and openness trade, financial sector development and trade openness, and trade openness and pollution in the case of European economies. From the causal link between GDP and environmental pollutants, they authorize the existence the validity of the environmental Kuznets curve hypothesis. Also, they substantiate out the feedback suggestion of the bidirectional causality amid trade openness and financial sector development. Besides, they discover the neutrality hypothesis linking carbon emissions and financial sector development inflows. They find the occurrence of the bidirectional nexus amid GDP and financial sector development and among GDP and trade openness in the European countries. Finally, Granger causality verifies that bidirectional causal connection is found among economic development, environmental degradation ( $\mathrm{CO} 2)$, financial progress, and trade openness.

Jamel and Maktouf (2017) check the causal link among economic growth (GDP), CO2 emissions (environmental degradation), financial development and trade openness by utilizing the ordinary least squares technique for a yearly panel data of 40 European economies, through the period of study beginning on 1985 to 2014. To examine this causal association, they utilize the Cobb-Douglas production function. Their empirical conclusions point to a bidirectional Granger causal connection among GDP and pollution, GDP and financial sector development, GDP and openness trade, financial sector development and openness trade and trade openness and pollution in the case of European economies. From the fundamental link amid GDP and environmental pollutants, they authorize the continuation of the environmental Kuznets curve hypothesis. Also, they prove the feedback suggestion of the bidirectional causality amid openness trade and financial sector development. Besides, they conclude the neutrality hypothesis linking $\mathrm{CO} 2$ emissions and financial sector development inflows. Finally, they show the occurrence of the bidirectional nexus amid GDP and financial sector development and amongst GDP and trade openness in the European economies.

\section{Model}

In this research, we will study the effect of economic development measured by the growth of gross domestic product (GDP) on pollution. This impact is studied while incorporating other control variables namely trade in goods and services (OC) as a measure of openness trade and domestic credit to the private sector (DF) as a financial development indicator.

In addition, we use in the same category of the control variables; the urban population calculated in thousands of people has also been utilized as an index of urbanization (U).

The integration of these variables is based on the Cobb Douglas production function, in which economic growth is calculated as a function of endogenous and exogenous factors.

Finally, the emission of carbon dioxide (CO2) was used as a measure of pollution. Annual data for all the above mentioned variables will be taken from the World Bank's database for the period through 1985 to 2015.

The study of the effect of economic development on pollution is based on the use of the Cobb-Douglas function, which is a widely employed economics function to represent the liaison between input and output. This function has been proposed and tested econometrically by the American economist Paul Douglas and the American mathematician Charles Cobb in 1928.

As part of a production function of two factors, the most generally used form is of the following form:

$$
Y=C \cdot K^{\alpha} \cdot L^{\beta}
$$

Where, $\mathrm{Y}$ is the level of production, $\mathrm{K}$ than the capital $\mathrm{L}$ in the workplace, and $\mathrm{c}, \alpha$ and $\beta$ are constants determined by technology.

Under the model of perfect competition, the $\alpha$ and $\beta$ coefficients correspond to the distribution of income between labor and capital. But the statistical evidence of the consistency of this model, conducted by Cobb and Douglas, also showed that the income distribution key between labor and capital is constant over time in developed countries. However, this constancy, clearly established at the time, is now in doubt.

Subsequently, the model used was as follows (Jamel and Derbali, 2016; Sy et al., 2016)

$$
\text { Polution }=f(P I B, D F, V C)
$$

Where, GDP refers to the growth rate of gross domestic product of each country and VC are the control variables. The different variables are expressed in natural logarithm. Thus, the econometric model can be presented as 
follows:

$$
L C O_{2}=\beta_{i 0}+\beta_{i 1} L P I B_{i t}+\beta_{i 2} L D F_{i t}+\sum_{j=2}^{p} \beta_{i j} X_{i t}+\varepsilon_{i t}
$$

Where, $\beta_{i 0}$ is the constant, $\beta_{i s}$ indicates the coefficient of each explanatory variable used in our research work with $\mathrm{s}=1, \ldots, \mathrm{p}, \varepsilon_{i t}$ is the error term and $X_{i t}$ is the vector of control variables such as trade openness, the consumption of energy, urbanization rate, foreign direct investment, the capital stock and inflation. i denotes the index of each country $(i=1, \ldots, 25) . t$ is the index of each year $(t=1, \ldots, 31)$.

\section{Data}

Our paper focuses on the determination of the impact of economic growth on pollution in European countries for the study period between 1985 and 2015. We will use annual panel data for a sample of 25 developed European countries. We summarize in Table 1 the list of developed European countries that will be utilized in this study.

We chose this sample is composed of European countries since this area is the richest in the world. It is composed by the most industrialized area of the world. Thus, Europe is the richest region and developed world, but it is not an economically homogeneous space: all European countries are developed countries: Ukraine and Moldova are the exception and are classified as a means for developing countries with an HDI (human development index) less than 0.8. The Western Europe and very prosperous Northern Europe contrasts with some poorer regions of Central Europe, Eastern Europe (Moldova, Ukraine, parts of Romania, Russia) and Europe South (Albania, Serbia, Macedonia, parts of Bulgaria, southern Italy,

And our choice is justified by the human development index since the majority of European countries have an index greater than 0.85 according to Figure 1 in 2015.

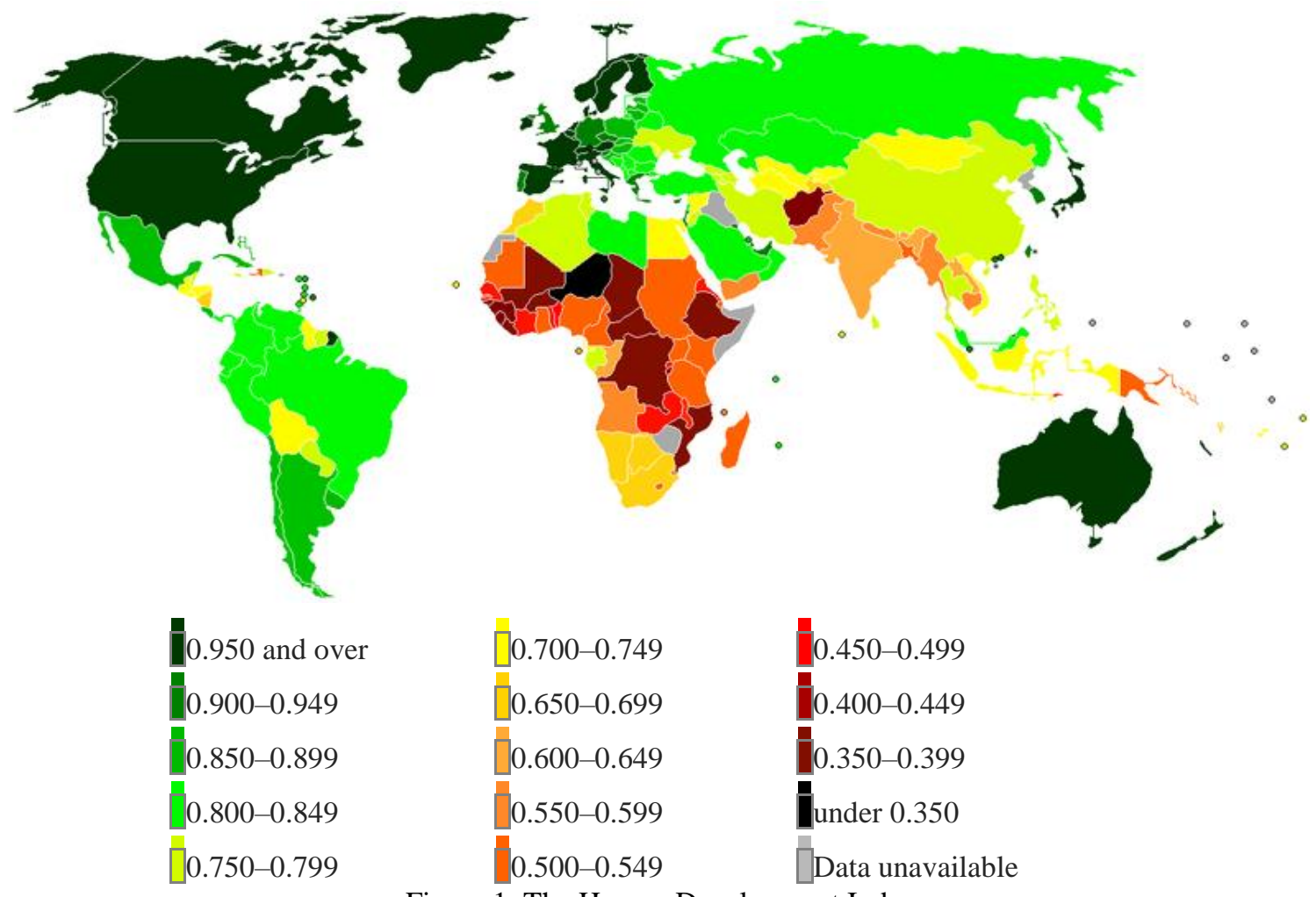

Figure 1. The Human Development Index

Source: United Nations Development Program (2015)

The richest regions belong to the European metropolis, vast triangle between London, Milan and Hamburg, and are the economic heart of Europe. Also, it is known as the "blue banana", the Rhine Axis or "European backbone". 
These regions, which experienced an early industrial revolution, are more urbanized and best equipped in terms of infrastructure (road and rail in particular) 7.8. Despite the crisis affecting certain industrial centers (e.g. parts of Belgium and northern France), the inhabitants of this part of Europe generally benefit from higher incomes.

We usually speak of Central and Eastern Europe to designate the former satellite states of the USSR. The Central European countries that recently joined the European Union have them, an industrial transfer from Western Europe, Germany and North Europe. The Eastern European regions, retraining after leaving the USSR, compared with a low capita income and sometimes high unemployment, but in sharp decline during the years 2009.

In general, European peripheral regions (southern Italy, Portugal, and Greece) are less rich than the center, although northern Europe, prosperous and located on the technological frontier, seems to be an exception.

Table 1. List of developed European countries

\begin{tabular}{|c|c|c|c|c|c|}
\hline & Name of the country & Surface $(\mathrm{km} 2)$ & Population (2014) & The population density (per km2) & Capital city \\
\hline 1 & Austria & 83.879 & 8504850 & 101.4 & Vienna \\
\hline 2 & 1 Belgium & 30.528 & 11198638 & 366.8 & Brussels \\
\hline 3 & Cyprus & 9,251 & 1117000 & 120.7 & Nicosia \\
\hline 4 & Czech republic & 78.866 & 10513209 & 133.3 & Prague \\
\hline 5 & Denmark & 42.916 & 5655750 & 131.8 & Copenhagen \\
\hline 6 & Estonia & 45.227 & 1315819 & 29.1 & Tallinn \\
\hline 7 & Finland & 338.424 & 5470820 & 16.2 & Helsinki \\
\hline 8 & a France & 551.695 & 66030000 & 115.8 & Paris \\
\hline 9 & germany & 357.168 & 80716000 & 226.0 & Berlin \\
\hline 10 & Greece & 131.957 & 10816286 & 82.0 & Athens \\
\hline 11 & Hungary & 93.030 & 9877365 & 106.2 & Budapest \\
\hline 12 & 믐 Iceland & 103.001 & 325.671 & 3.2 & Reykjavík \\
\hline 13 & ireland & 70.273 & 4609600 & 65.6 & Dublin \\
\hline 14 & Italy & 301.338 & 60782668 & 201.7 & Rome \\
\hline 15 & luxembourg & 2,586 & 549.680 & 212.6 & luxembourg \\
\hline 16 & Netherlands & 41.543 & 16856620 & 405.8 & Amsterdam \\
\hline 17 & Norway & 385.178 & 5136700 & 13.3 & Oslo \\
\hline 18 & Poland & 312.679 & 38483957 & 123.1 & Warsaw \\
\hline 19 & (8) Portugal & 92.212 & 10427301 & 113.1 & Lisbon \\
\hline 20 & Slovakia & 49.035 & 5415949 & 110.5 & Bratislava \\
\hline 21 & Slovenia & 20.273 & 2061085 & 101.7 & Ljubljana \\
\hline 22 & spain & 504.645 & 46704314 & 92.6 & Madrid \\
\hline 23 & Eweden & 449,964 & 9716962 & 21.6 & Stockholm \\
\hline 24 & + Swiss & 41.285 & 8183800 & 198.2 & Bern \\
\hline 25 & UK & 243.610 & 64100000 & 263.1 & London \\
\hline
\end{tabular}

Source: IMF (2016)

All of the descriptive statistics of the indicators used in our research are summarized in Table 2 for the developed European countries during the period of study.

For the group of European countries and developed according to the results of Table 2, we noticed that the LCO2 variable, which expresses logarithm of $\mathrm{CO} 2$ emissions, can reach a maximum value 3.311344. As its minimum value is 1.005861 . Its risk is 0.339933 . 
The LPIB variable, which measures the logarithm of the GDP growth rate may reach a maximum value 11.36358. While its minimum value is 8.391950 . Its risk is 0.663097 .

The LCE variable, which measures the logarithm of the energy consumption for non developed European countries, may reach a maximum value 9.840280. As its minimum value is 6.997467. Its risk is 0.429237.

The FLA variable, which measures the logarithm of the level of financial development, can reach a maximum value 6.065274. While it's minimum value is -5.696879 . It's risk is 1.250932 .

LIDE variable, which measures the logarithm of foreign direct investment, can reach a maximum value 5.739996. While it's minimum value is 0.000000 . It's risk is measured by the standard deviation is 0.720456 .

Both statistics of skewness and kurtosis, we can conclude that all variables used in the present research work are characterized by non-normal distribution. Then, the asymmetry coefficients indicate that all variables are shifted to the left with the negative sign of asymmetry coefficients and is far from symmetrical except for the three indicators LCO2, LOC and LCE that are geared to the right with the positive sign of asymmetry coefficients. In addition, the leptokurtic coefficient shows that for all variables employed in this paper indicate the presence of a high peak or a large tail in their volatilities.

Also, the positive indication of estimation coefficients of Jarque-Bera statistics indicates that we can refuse the null hypothesis of the normal distribution of the variables employed in this study. In fact, the elevated value of the coefficients of the Jarque-Bera statistic reflects that the series are not normally distributed at a threshold of $1 \%$.

The results shown by the three statistics suggest that all variables utilized in this study are not normally distributed in the case of developed European countries throughout the period from 1985 to 2015.

In pursuit of our empirical analysis, we conduct a test of the correlation between the different variables used in the case of developed European countries during the period of study from 1985 to 2015. Table 3 summarizes the results relating to the Pearson correlation test.

Thus, the correlation coefficients used to give a summary measure of the intensity of the liaison between two characters and sense when this relationship is boring.

In addition, the results of correlation that all coefficients between the explanatory variables do not surpass the tolerance limit (0.7), which does not cause problems in the estimation of the model. That is to say, we can integrate the different variables employed in the same model.

A study of the causal link among economic development and pollution in developed European countries requires prior perform stationary tests to conclude the order of integration of each indicators. Before processing a time series, it is necessary to examine the stochastic characteristics. If these characteristics, that is to declare - the expectation and variance - are modified above time, the variable is considered as non-stationary in the case of an invariant stochastic process, the series is then stationary.

The results of the Levin-Lin-Chu test (LLC), Im-Pesaran-Shin test (IPS), Fisher-ADF test and Fisher-PP test applied to the variables are shown in Table 4 for the developed European countries.

Acceptance or refusal of the null hypothesis of the different tests is based on the value of probability and the indicated test statistics. These probabilities are compared by a $10 \%$ threshold. If these probabilities are fewer than $10 \%$, then we refuse the null hypothesis and if these probabilities are superior than $10 \%$, then we admit the null hypothesis.

For developed European countries and in Table 4, we observe that only two variables LPIB and LCE are non-stationary in level according to the test of Levin-Lin-Chu but all indicators used in this paper are stationary in first difference according to this test.

According to statistics of the test-Im Pesaran-Shin (IPS) test ADF-Fisher and the test of PP-Fisher, we can conclude that only four variables FLA, LIDE, LINF and LU are stationary in level. But first difference, all variables are stationary according to these three tests. Thereafter, all the variables are integrated of order 1 . Thus, we can advance with the cointegration test. 
Table 2. Descriptive statistics for developed European countries

\begin{tabular}{lrrrrrrrrr}
\hline & LCO2 & LDF & LIDE & LINF & LOC & LPIB & LSK & LU & LCE \\
\hline Mean & 2.127313 & 0.751679 & 4.271883 & 1.048004 & 4.408486 & 10.11090 & 2.375731 & -0.395732 & 8.234923 \\
Median & 2.079290 & 0.711802 & 4.376396 & 0.984499 & 4.361559 & 10.27027 & 2.571368 & -0.121982 & 8.195946 \\
Maximum & 3.311344 & 6.065274 & 5.739996 & 6.319655 & 5.917387 & 11.36358 & 5.919903 & 1.205764 & 9.840280 \\
Minimum & 1.005861 & -5.696879 & 0.000000 & -28.94033 & 3.525479 & 8.391950 & -3.793771 & -4.614765 & 6.997467 \\
Std. Dev. & 0.339933 & 1.250932 & 0.720456 & 1.553748 & 0.456544 & 0.663097 & 1.819433 & 0.916152 & 0.429237 \\
skewness & 0.682344 & -0.140631 & -1.705785 & -9.126357 & 0.504057 & -0.629751 & -0.637919 & -1.445124 & 0.640854 \\
kurtosis & 4.321457 & 4.206863 & 10.95208 & 180.9030 & 3.111689 & 2.650659 & 3.185460 & 5.977498 & 4.121064 \\
Jarque-Bera & 116.5283 & 49.58794 & 2417.817 & 1032773. & 33.22068 & 55.16660 & 53.67387 & 556.0312 & 93.63164 \\
Probability & $0.000000 *$ & $0.000000 *$ & $0.000000 *$ & $0.000000 *$ & $0.000000 *$ & $0.000000 *$ & $0.000000 *$ & $0.000000 *$ & $0.000000 *$ \\
Sum & 1648.668 & 582.5514 & 3310.710 & 812.2030 & 3416.576 & 7835.945 & 1841.192 & -306.6925 & 6382.066 \\
Sum Sq. Dev. & 89.43889 & 1211.179 & 401.7497 & 1868.540 & 161.3265 & 340.3257 & 2562.199 & 649.6450 & 142.6053 \\
observations & 775 & 775 & 775 & 775 & 775 & 775 & 775 & 775 & 775 \\
\hline
\end{tabular}

Note: $(*)$ are significant values at a threshold of $1 \%$.

Table 3. The correlation matrix for developed European countries

\begin{tabular}{lrrrrrrrrr}
\hline & LCO2 & LDF & LIDE & LINF & LOC & LPIB & LSK & LU & LCE \\
\hline LCO2 & 1.000000 & 0.278870 & -0.099142 & -0.021480 & 0.407358 & 0.137253 & -0.119378 & 0.032678 & 0.526315 \\
LDF & 0.278870 & 1.000000 & 0.109938 & -0.151631 & 0.568514 & 0.091746 & 0.115856 & 0.186582 & 0.173852 \\
LIDE & -0.099142 & 0.109938 & 1.000000 & -0.303582 & 0.076379 & 0.499680 & 0.363730 & 0.177899 & 0.017187 \\
LINF & -0.021480 & -0.151631 & -0.303582 & 1.000000 & -0.166768 & -0.355833 & -0.291696 & -0.002415 & -0.069892 \\
LOC & 0.407358 & 0.568514 & 0.076379 & -0.166768 & 1.000000 & 0.144417 & -0.163140 & 0.249062 & 0.285672 \\
LPIB & 0.137253 & 0.091746 & 0.499680 & -0.355833 & 0.144417 & 1.000000 & 0.425109 & 0.132127 & 0.503731 \\
LSK & -0.119378 & 0.115856 & 0.363730 & -0.291696 & -0.163140 & 0.425109 & 1.000000 & -0.024049 & 0.083723 \\
LU & 0.032678 & 0.186582 & 0.177899 & -0.002415 & 0.249062 & 0.132127 & -0.024049 & 1.000000 & 0.075779 \\
LCE & 0.526315 & 0.173852 & 0.017187 & -0.069892 & 0.285672 & 0.503731 & 0.083723 & 0.075779 & 1.000000 \\
\hline
\end{tabular}

Table 4. The unit root test for developed European countries

\begin{tabular}{|c|c|c|c|c|c|c|c|c|}
\hline & \multicolumn{2}{|c|}{ Levin, Lin and Chu test } & \multicolumn{2}{|c|}{ Im Pesaran and Shin test } & \multicolumn{2}{|c|}{ Fisher-ADF test } & \multicolumn{2}{|c|}{ Fisher-PP test } \\
\hline & In level & In the first difference & In level & In the first difference & In level & In the first difference & In level & In the first difference \\
\hline $\mathrm{LCO} 2$ & $-1.99132 * *$ & $-10.0135 *$ & -0.18744 & $-13.4939 *$ & 62.4743 & $273549 *$ & $75.8540 * *$ & $576168 *$ \\
\hline LDF & $-3.54839 *$ & $-7.95865 *$ & $-2.14304 * *$ & $-7.00217 *$ & $72.1094 * *$ & $157951 *$ & $* 96.0630$ & $251138 *$ \\
\hline LIDE & $-3.27169 *$ & $-15.0276 *$ & $-4.13400 *$ & $-19.8093 *$ & *93.4536 & $413149 *$ & $185031 *$ & $719988 *$ \\
\hline LINF & $-1.87740 * *$ & $-15.9591 *$ & $-1.4994 * * *$ & $-19.2103 *$ & $70.2090 * *$ & $400253 *$ & $116535 *$ & $671116 *$ \\
\hline LOC & $-2.49506 *$ & $-4.85462 *$ & 0.61191 & $-12.0263 *$ & 32.7873 & $238635 *$ & 21.1950 & $367802 *$ \\
\hline LPIB & -1.05050 & $-8.78113 *$ & 1.04897 & $-6.89834 *$ & 27.5561 & 853234 * & 40.8874 & $881724 *$ \\
\hline LSK & $-3.37852 *$ & $-13.3311 *$ & -1.06058 & $-12.3459 *$ & 49.8572 & $244379 *$ & 38.5970 & 371299 \\
\hline $\mathrm{LU}$ & $-2.62319 *$ & $-11.2996 *$ & $-4.48602 *$ & $-13.9293 *$ & $102246 *$ & $282807 *$ & $111306 *$ & $425765 *$ \\
\hline LCE & 4.27379 & $-6.15483 *$ & 4.79995 & $-3.19096 *$ & 24.2644 & $* 82.1370$ & 29.1594 & $215571 *$ \\
\hline
\end{tabular}

Note: In this test, the p-value is compared to $10 \%$. If the probabilities $<10 \%$ therefore we reject the null hypothesis and the probabilities> $10 \%$ then we accept the null hypothesis. With the null hypothesis all series are non-stationary. $(*),(* *)$ and $(* * *)$ are significant values for the $1 \%, 5 \%$ and $10 \%$, respectively.

\section{Empirical Results}

\subsection{Testing Cointegration}

The analytical part is devoted to the presentation of the test results of cointegration. The tests of cointegration of Kao and Fisher are applied to ensure the long-term nexus between the variables employed in this research project to examine the effect of economic development on pollution in the case of developed European countries.

Thus, the long-term link among the development of the economic sphere and the environmental sphere can be easily understood with a cointegration relationship between the two variables. Nevertheless, we must first ensure 
that the requirements are fulfilled and it is always possible to find a long-term relationship between financial variables and real variables; this can be verified from a co-integration test.

The Kao test is based on the t-ADF statistic. But Fisher's test is based on the Fisher statistical test track and Fisher Statistic of max-eigen test. The empirical results of the cointegration test for developed European countries are presented in Table 5.

In the case of developed European countries, Kao test confirms the long-term link among the different variables utilized in our research mainly between economic development and pollution. Fisher test results corroborate the existence of a long-term nexus between GDP and emissions of CO2 in developed European countries for the study period from 1985 to 2015.

According to the results of Table 5, we have confirmed the presence of a cointegration nexus between the different series studied. Indeed, the results of the null hypothesis test of no-cointegration was rejected at the $5 \%$ threshold, which explains the existence of a cointegration link.

The results are established by the results of eigenvalue. The results of these tests can conclude the exercise of an error correction model. Also, to test the effect of economic development on environmental degradation in developed European countries, we will perform two FMOLS and DOLS estimation.

Table 5. The cointegration test of the impact of economic growth on pollution for developed European countries

\begin{tabular}{lllll}
\hline Kao Residual Cointegration Test & \multicolumn{4}{l}{ Fisher Johansen Cointegration Test Panel } \\
\hline Statistics & $\begin{array}{l}\text { Fisher Stat. * } \\
\text { (From test track) }\end{array}$ & Prob. & $\begin{array}{l}\text { Fisher Stat. * } \\
\text { (From max-eigen test) }\end{array}$ & Prob. \\
\hline$-3.471189(0.0003) *$ & 645.5 & $(0.0000) *$ & 1863. & $(0.0000) *$ \\
\hline
\end{tabular}

Note: $(*)$ are significant values at a threshold of $1 \%$.

\subsection{FMOLS Estimates and DOLS}

In this part, we perform two estimates by FMOLS and DOLS methods for the case of selected groups of economies in this paper. Tables 6 and 7 summarize the estimation results of the impact of economic development on pollution in the case of developed European countries, respectively the technical FMOLS and DOLS.

The technique FMOLS in panel proposed by Pedroni $(1996,2000)$ solves problems of heterogeneity in the sense that it allows the use of heterogeneous cointegrating vectors. Also, the FMOLS estimator takes into description the existence of the constant term and the possible presence of correlation among the error term and differences estimators.

Adjustments are complete to this effect on the dependent variable and long-term parameters obtained by estimating the fitted equation. In the case of panels, long term coefficients from the FMOLS art are obtained by the average group of estimators with respect to the sample size $(\mathrm{N})$.

So, one of the problems of the OLS estimator is derived from the correlation between the explanatory variables and endogeneity. One way to correct these problems is to use the DOLS estimator. This method is to integrate the cointegration delays and advances of the explanatory variable taking orthogonalizing difference to the residue of the cointegration relationship; i.e. to eliminate the link among the explanatory variables and the error term.

Then, the coefficients of determination for the two estimates is superior than 0.7 (0.947960 and 0.996949), Therefore, both estimated models are characterized by a good linear fit.

The first is the variable For FMOLS estimate, we notice that four variables are significant, but with different signs for the group of developed European countries.

Indeed, the GDP growth rate has a positive and important effect on emissions of $\mathrm{CO} 2$ at a threshold of $1 \%$ in the case of developed countries. This means that, if economic growth increases by one while the $\mathrm{CO} 2$ emissions increase by 0.143860 units at time $t$ for the case of the group of developed European countries.

LEC variable which measures the level of energy utilization is statistically significant and positive at a $1 \%$ level. So if energy utilization increases by one then, environmental degradation increases 0.525440 units in developed European countries. 
In the same analytical framework, we find that, statistically significant and positive at a $1 \%$ level. The LIDE variable measuring foreign direct investment has a negative effect on emissions of $\mathrm{CO} 2$ at a $10 \%$ threshold. That is to say, if the level of FDI increases by ten units, then the CO2 emissions decrease of 0.010375 units.

LOC variable which measures the commercial opening rate is statistically significant and negative to a threshold of $1 \%$. So if trade opening increments so, environmental degradation decreases 0.259711 units.

Table 6. Estimated FMOLS for developed European countries

\begin{tabular}{|c|c|c|c|c|}
\hline Variable & Coefficient & Std. error & Does Statistic & Prob. \\
\hline LIDE & -0.010375 & 0.005748 & -1.805069 & $0.0715 * * *$ \\
\hline LDF & 0.000500 & 0.009608 & 0.051994 & 0.9585 \\
\hline LINF & -0.004828 & 0.003620 & -1.333594 & 0.1828 \\
\hline LOC & -0.259711 & 0.037994 & -6.835634 & $0.0000 *$ \\
\hline LPIB & 0.143860 & 0.044864 & 3.206586 & $0.0014 *$ \\
\hline LSK & -0.005796 & 0.004813 & -1.204150 & 0.2289 \\
\hline LU & 0.002477 & 0.006650 & 0.372510 & 0.7096 \\
\hline LCE & 0.525440 & 0.043556 & 12.06356 & $0.0000 *$ \\
\hline R-squared & 0.947960 & \multicolumn{2}{|c|}{ Mean dependent var } & 2.127647 \\
\hline Adjusted R-squared & 0.945637 & \multicolumn{2}{|c|}{ SD dependent var } & 0.336522 \\
\hline $\mathrm{SE}$ of regression & 0.078463 & \multicolumn{2}{|c|}{ Sum squared resid } & 4.414182 \\
\hline Durbin-Watson stat & 0.418460 & \multicolumn{2}{|c|}{ Long-run variance } & 0.016528 \\
\hline
\end{tabular}

Note: significant value to a threshold: $(*) 1 \% ;(* *) 5 \%(* * *) 10 \%$.

The first is the variable For the DOLS estimation, we find that there are three variables that are significant, but with different signs for the group of European countries.

Thus, always the GDP growth rate has a positive and important effect on $\mathrm{CO} 2$ emissions at a threshold of $1 \%$ for the case of non-developed countries. This means that, if economic growth increases by one while the $\mathrm{CO} 2$ emissions increase 0.227367 units for the case of the group of developed countries.

LCE variable which expresses the level of energy utilization is statistically significant and positive at a $1 \%$ level. So if energy consumption in developed European countries increased by one then, environmental degradation increases 0.266434 units.

LOC variable which measures the commercial opening rate is statistically significant and negative to a threshold of $1 \%$. So if trade openness increases by one then, pollution decreases 0.384999 units.

Table 7. Estimated DOLS to developed European countries

\begin{tabular}{lllll}
\hline Variable & Coefficient & Std. error & Does Statistic & Prob. \\
\hline LIDE & 0.001743 & 0.009400 & 0.185427 & 0.8530 \\
LDF & -0.001252 & 0.015744 & -0.079536 & 0.9367 \\
LINF & 0.006846 & 0.004468 & 1.532217 & 0.1266 \\
LOC & -0.384999 & 0.051133 & -7.529318 & $0.0000 *$ \\
LPIB & 0.227367 & 0.057543 & 3.951277 & $0.0001 *$ \\
LSK & -0.003870 & 0.005729 & -0.675437 & 0.5000 \\
LU & -0.006529 & 0.008114 & -0.804695 & 0.4217 \\
LCE & 0.266434 & 0.044867 & 5.938313 & $0.0000 *$ \\
\hline R-squared & 0.996949 & Mean dependent var & 2.127313 \\
Adjusted R-squared & 0.991411 & SD dependent var & 0.339933 \\
SE of regression & 0.031503 & Sum squared resid & 0.272920 \\
Long-run variance & 0.000535 & &
\end{tabular}

Note: significant value to a threshold: $(*) 1 \% ;(* *) 5 \%(* * *) 10 \%$. 


\subsection{The Test of Granger Causality}

To investigate the causal link among economic variables in the using model, we employ a causality test of Granger initiated in 1969 that has become above time an interesting conceptual framework than the one for the highlight econometric links.

In general, based on this test, we can prove if there is a close liaison among the variables of economic growth and pollution.

To supply a robust analysis of the relationship between pollution and fluctuations in GDP growth rate, we start to apply some trying Granger causality.

Therefore, we must check whether the cause economic growth the movement of $\mathrm{CO} 2$ emissions or pollution due to economic growth.

Acceptance or rejection of the null hypothesis of Granger causality test is based on a threshold of 5\%. If the probability of Granger causality test is less than 5\% in this case we reject the null hypothesis and if the probability is superior than $5 \%$ then we recognize the null hypothesis of no causality.

Table 8 summarizes the results of causality test for the case of developed European countries for the study period of 1985 to 2015.

According to this table, we find that it is growth that causes Granger changes in $\mathrm{CO} 2$ emissions $(0.0050<0.05)$ and not the reverse $(0.7151>0.05)$. In this case, we can say that there is a unidirectional link between economic development and pollution in the case of developed European countries.

We observe that there is a bidirectional nexus between energy consumption and pollution Granger $(0.0023<5 \%$ and $0.0002<5 \%$ ).

We find that it is $\mathrm{CO} 2$ emissions that causes Granger variation IDEs $(0.0139<0.05)$ and not the reverse $(0.9858>$ $0.05)$. In this case, we can say that there is a unidirectional relationship between IDEs and pollution.

Thus, there is no causal link between financial development and pollution Granger as their probability values are above 0.05 (0.3525 and 0.2604) allow to accept the null hypothesis of the test.

Also, there is no causal link between inflation and $\mathrm{CO} 2$ emissions of Granger as their probability values are above 0.05 (0.1187 and 0.9843) allow to accept the null hypothesis test.

Similarly, there is no causal liaison between trade openness and pollution Granger as their probability values are above 0.05 ( 0.9085 and 0.1784$)$ allow to accept the null hypothesis test.

Moreover, there is no causal link between capital stock and pollution Granger as their probability values are above 0.05 (0.1644 and 0.1246) allow to accept the null hypothesis test.

Similarly, there is no causal liaison between urbanization and pollution Granger as their probability values are above 0.05 (0.9643 and 0.1340) allow to accept the null hypothesis test.

Table 8. Granger causality test for developed European countries

\begin{tabular}{llll}
\hline Null hypothesis: & Obs & F-Statistic & Prob. \\
\hline LIDE does not Cause LCO2 & 725 & 0.01426 & 0.9858 \\
LCO2 does not Cause LIDE & & 4.30185 & 0.0139 \\
DFL does not Cause LCO2 & 725 & 1.04409 & 0.3525 \\
LCO2 does not Cause LDF & & 1.34794 & 0.2604 \\
The INF does not Cause LCO2 & 725 & 2.13767 & 0.1187 \\
LCO2 does not Cause LINF & & 0.01583 & 0.9843 \\
LOC does not Cause LCO2 & 725 & 0.09596 & 0.9085 \\
LCO2 does not Cause LOC & & 1.72788 & 0.1784 \\
LPIB does not Cause LCO2 & 725 & 3.00621 & 0.0500 \\
LCO2 does not Cause LPIB & & 0.33553 & 0.7151 \\
LSK does not Cause LCO2 & 725 & 1.80969 & 0.1644 \\
\hline
\end{tabular}




\begin{tabular}{llll}
\hline LCO2 does not Granger Cause LSK & & 2.08872 & 0.1246 \\
LU does not Granger Cause LCO2 & 725 & 0.03631 & 0.9643 \\
LCO2 does not Granger Cause LU & & 2.01570 & 0.1340 \\
LCE does not Granger Cause LCO2 & \multirow{2}{*}{725} & 6.14704 & 0.0023 \\
LCO2 does not Granger Cause LCE & & 8.78431 & 0.0002 \\
\hline
\end{tabular}

\section{Conclusion}

Our goal in the present paper is to scrutinize empirically the effect of economic development on pollution for all developed European countries through the period of study from 1985 to 2015.

At the descriptive level, we notice that the rate of economic development and $\mathrm{CO} 2$ emissions is higher in developed European countries. This was well justified by the different descriptive statistics such as maximum, minimum and the level of risk. Furthermore, we demonstrate that the different series employed do not follow a normal distribution based Skweness statistics, kurtosis and Jarque-Bera.

In addition, we find that all variables used in this paper are stationary in first differences according to the used tests in our empirical framework. Thereafter, all the variables employed are integrated of order 1 . And then, we progress to the cointegration test.

We use the cointegration tests of Kao and Fisher to examine the long-term relationship linking the variables used to test the effect of economic development on pollution in the case of developed European countries. According to the results of the two tests, we confirm the subsistence of a cointegration relationship among the different indicators studied.

Then, we utilize the methods FMOLS and DOLS and the Granger causality test to empirically test the effect of changes in economic development on environmental degradation in developed European countries. The results find by these two techniques have confirmed the hypothesis of basic ECK which assumes the presence of a bidirectional nexus among economic development and $\mathrm{CO} 2$ emissions in developed European countries. In addition, we find that there is a two-way causal link among energy utilization and pollution in developed European countries.

\section{Acknowledgments}

I think to knowledge the editor in chief and the anonymous reviewers for their helpful suggestions and remarks.

\section{References}

Baranzini, A., Weber, S., Bareit, M., \& Mathys, N. A. (2013). The causal relationship between energy use and economic growth in Switzerland. Energy Economics, 36(2), 446-470.

Charfeddine, L., \& Ben Khediri, K. (2016). Financial development and environmental quality in UAE: Cointegration with structural breaks. Renewable and Sustainable Energy Reviews, 55(3), 1322-1335. https://doi.org/10.1016/j.rser.2015.07.059

Chen, S. T., Kuo, H. I., \& Chen, C. C. (2007). The relationship between GDP and electricity consumption in 10 Asian countries. Energy Policy, 35(4), 2611-2621. https://doi.org/10.1016/j.enpol.2006.10.001

Farhani, S., Muhammad, S., Sbia, R., \& Chaibi, A. (2014). What does MENA region initially need: grow output or mitigate $\mathrm{CO} 2$ emissions? Economic Modeling, 38(2), 270-281. https://doi.org/10.1016/j.econmod.2014.01.001

Ghosh, S. (2010). Examining carbon emissions-economic growth nexus for India: a multivariate cointegration approach. Energy Policy, 38(6), 2613-3130. https://doi.org/10.1016/j.enpol.2010.01.040

Granger, C. W. J. (1969). Investigating Causal Relations by Econometric Models and Cross-Spectral Methods,' Econometrica, Econometric Society, 37(3), 424-438.

Jamel, L., \& Derbali, A. (2016). Do energy consumption and economic growth lead to environmental degradation? Evidence from Asian Economies, Cogent Economics \& Finance, 4(1), 1170653. https://doi.org/10.1080/23322039.2016.1170653

Jamel, L., \& Maktouf, S. (2017). The nexus between economic growth, financial development, trade openness, and $\mathrm{CO} 2$ emissions in European countries. Cogent Economics \& Finance, 5, 1341456. https://doi.org/10.1080/23322039.2017.1341456 
Jamel, L., \& Maktouf, S. (2017). The nexus between economic growth, financial development, trade openness, and $\mathrm{CO} 2$ emissions in European countries. International Journal of Management and Network Economics, 4(1), 67-94. https://doi.org/10.1504/IJMNE.2017.087584

Kuznets, S. (1955). Economic growth and inequality. American Economic Review, 49(1), 1-28.

Omri, A. (2013). CO2 emissions, energy consumption and economic growth nexus in MENA countries: Evidence from simultaneous equations models. Energy Economics, 40(6), 657-664. https://doi.org/10.1016/j.eneco.2013.09.003

Pedroni, P. (1996). Fully Modified OLS for Heterogeneou s Cointegrated Panels and the Case of Purchasing Power Parity. Indiana University, Working papers in economics No. 96-020.

Pedroni, P., (2000). Fully Modi. ed OLS for Heterogeneou s Cointegrated Panels. Advances in Econometrics, 15, 93-130. https://doi.org/10.1016/S0731-9053(00)15004-2

Shahbaz, M., Hye, Q. M. A., Tiwari, A. K., \& Leitão, N. C. (2013). Economic growth, energy consumption, financial development, international trade and $\mathrm{CO} 2$ emissions in Indonesia', Renewable and Sustainable Energy Reviews, 25(9), 109-121. https://doi.org/10.1016/j.rser.2013.04.009

Stern, D. I. (1993). Energy growth in the USA: a multivariate approach', Energy Economics, 15(2), 137-150. https://doi.org/10.1016/0140-9883(93)90033-N

Sy, A., Tinker, T., Derbali, A., \& Jamel, L. (2016). Economic growth, financial development, trade openness, and $\mathrm{CO} 2$ emissions in European countries. African Journal of Accounting, Auditing and Finance, 5(2), 155-179. https://doi.org/10.1504/AJAAF.2016.078320

Wolde-Rufael, Y. (2005). Energy demand and economic growth: the African experience', Journal of Policy Modeling, 27(8), 891-903. https://doi.org/10.1016/j.jpolmod.2005.06.003

Yuan, J., Zhao, C., Yu, S., \& Hu, Z. (2007). Electricity consumption and economic growth in China: cointegration and co-feature analysis. Energy Economics, 29(6), 1179-1191. https://doi.org/10.1016/j.eneco.2006.09.005

\section{Copyrights}

Copyright for this article is retained by the author(s), with first publication rights granted to the journal.

This is an open-access article distributed under the terms and conditions of the Creative Commons Attribution license (http://creativecommons.org/licenses/by/4.0/). 